\title{
Erzbischof Celestino Migliore, Apostolischer Nuntius in Polen - Doktor honoris causa der Päpstlichen Universität Johannes Paul II. in Krakau
}

Am 1. Juli 2015 fasste der Senat der Päpstlichen Universität Johannes Paul II. in Krakau (UPJPII) auf Antrag der Fakultät für Kanonisches Recht den Beschluss, Erzbischof Celestino Migliore den Ehrentitel Doktor honoris causa der Päpstlichen Universität Johannes Paul II. in Krakau zu verleihen. Erzbischof C. Migliore, der 25. Doktor honoris causa der Päpstlichen Universität Johannes Paul II. in Krakau, ist seit 2002 Erzbischof und Diplomat des Vatikan, seit 2010 fungiert er als Apostolischer Nuntius in Polen sowie als Dekan des Diplomatischen Korps der Volksrepublik Polen.

Der Verleihung des Ehrentitels gingen im Einklang mit den bestehenden Vorschriften das nihil obstat der Kongregation für das Katholische Bildungswesen sowie zwei positive Rezensionen durch H. H. Prof. Dr. hab. Tomasz Rozkrut (Dekan der Fakultät für Kanonisches Recht an der Päpstlichen Universität Johannes Paul II. in Krakau) und H. H. Prof. Dr. hab. Henryk Stawniak (Dekan der Fakultät für Kanonisches Recht an der Kardinal-Stefan-Wyszyński-Universität in Warschau) voraus. Als Laudator wurde H. H. Prof. Dr. hab. Jan Maciej Dyduch (Fakultät für Kanonisches Recht an der Päpstlichen Universität Johannes Paul II. in Krakau) auserwählt.

H. H. Prof. T. Rozkrut schrieb in seiner Rezension unter anderem: „Bei der Aufzählung aller Auszeichnungen ist hervor zu heben, dass Erzbischof Celestino Migliore bereits die Ehrendoktorwürde der St. John`s University in New York (26. Januar 2006) erhalten hat - als Anerkennung seiner Persönlichkeit und 


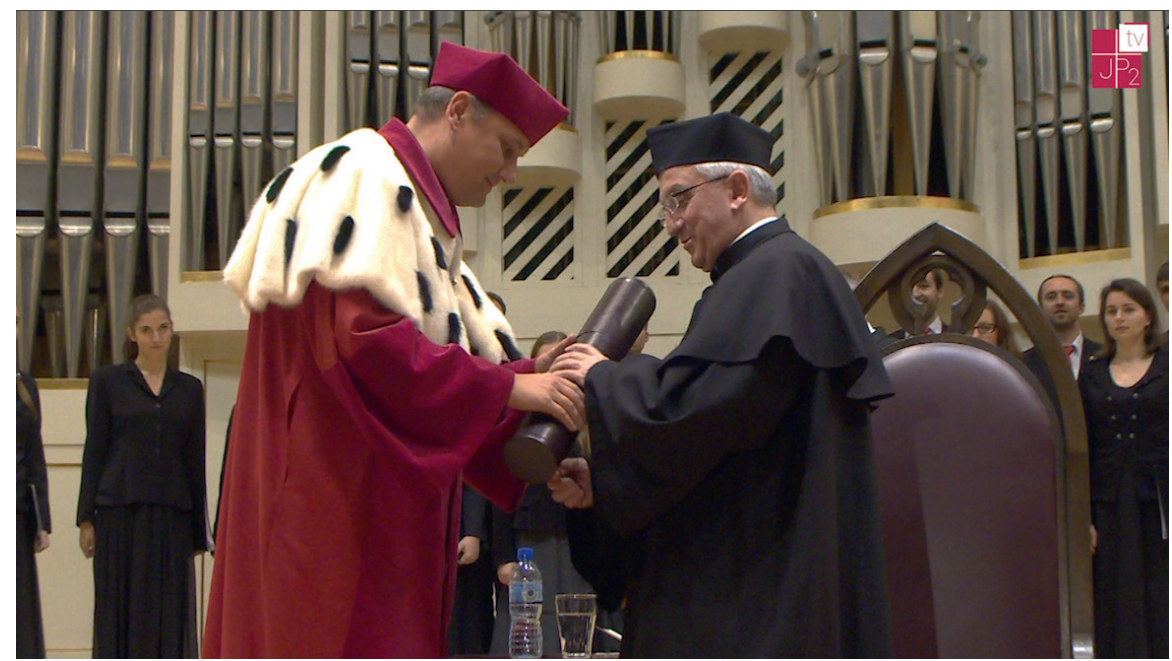

seines Wirkens von Seiten der amerikanischen Hochschule. Darüber hinaus wurde er am 19. Januar 1999 mit dem Verdienstorden zweiter Klasse der Republik Italien geehrt. Am gleichen Tag, als die Konklusion der vorgestellten Rezension geschrieben wurde, erhielt Erzbischof Celestino Migliore die Ehrendoktorwürde der Päpstlichen Theologischen Fakultät in Breslau. Die angeführten Ehrungen gehen zweifellos daraus hervor, dass Erzbischof Celestino Migliore die Norm $363 \$ 1$ im Kodex des Kanonischen Rechts in jeder Hinsicht bestens erfüllt, die da lautet: 'Den Gesandten des Papstes wird das Amt übertragen, den Papst selbst bei den Teilkirchen oder auch bei den Staaten und öffentlichen Autoritäten, zu denen sie entsandt sind, auf Dauer zu vertreten '”. Dagegen unterstrich der zweite Rezensent, H. H. Prof. Stawniak, in seinem Text unter anderem Folgendes: „Zusammenfassend ist festzustellen, das Erzbischof Celestino Migliore eine herausragende Persönlichkeit der Weltdiplomatie und eine wahrhafte Autorität auf diesem Gebiet ist. Sein ausnehmendes Wissen, sein aktives Engagement und Wirken für den Apostolischen Stuhl wie auch für die Sache der Kirche in Polen bestätigen nur zu Recht, dass er zum Kreis außergewöhnlicher Persönlichkeiten zu zählen ist. Ich möchte darauf aufmerksam machen, dass Erzbischof Celestino Migliore, Apostolischer Nuntius in Polen, auf Grund der hier angeführten persönlichen und diplomatisch-wissenschaftlichen Wesensvorzüge objektiv unter allen Aspekten würdig ist, die höchste Auszeichnung zu erhalten, die der Senat und die gesamte Gemeinschaft der Päpstlichen Universität Johannes Paul II. in Krakau vergeben können. Die Initiative, ihm den Titel Doktor honoris 
causa zu verleihen, betrachte ich als bedeutungsvoll und in jeder Hinsicht fundiert".

Die höchste akademische Auszeichnung, der Ehrentitel Doktor honoris causa, wurde Erzbischof Celestino Migliore insbesondere zuerkannt:

- für die kompetente Repräsentierung des Bischofs von Rom sowie des Apostolischen Stuhls in internationale Foren im Bewusstsein der Verantwortung für das gemeinsame Wohl aller und die Würde jedes einzelnen Menschen;

- für seine wichtigen und bedeutsamen Auftritte bei den Vereinten Nationen, die mit klarer und deutlicher Stimme auf das Magisterium des Bischofs von Rom und des Apostolischen Stuhls bei der Verteidigung der vorrangigsten Werte verweisen;

- für die bereitwillige und aktive Teilnahme an den verschiedensten Konferenzen und Wissenschaftskongressen;

- für sein lebendiges, ideenreiches, kluges und verantwortungsvolles Zusammenwirken zum Wohl der Kirche in Polen, für seine verlässliche institutionelle Arbeit, die mit der Verbreitung der päpstlichen Dokumente in der lokalen Kirche einher geht;

- für die während der letzten fünf Jahren ausgezeichnete Erfüllung seiner Aufgabe als Apostolischer Nuntius in Polen, durch die Erzbischof Dr. Celestino Migliore zweifellos als herausragende Persönlichkeit der vatikanischen Diplomatie mit seinem fundierten Wissen und seinen erworbenen Erfahrungen auf bedeutsame Weise die Gestaltung zeitgemäßer Beziehungen zwischen Staat und Kirche vor allem im Hinblick auf das gemeinsame Wohl beeinflusst.

Die feierliche Verleihung der Ehrendoktorwürde an Erzbischof Celestino Migliore durch die Päpstliche Universität Johannes Paul II. in Krakau fand am 16. Oktober 2015 statt, am 37. Jahrestag der Wahl von Kardinal Karol Wojtyła zum Papst, und wurde in die Inauguration des neuen akademischen Jahres an der Päpstlichen Universität Johannes Paul II. in Krakau eingebunden. Zunächst verlas H. H. Prof. Dr. hab. Wojciech Misztal, Prorektor, den Beschluss des Senats der UPJPII, der zur Auszeichnung mit dem Titel Doktor honoris causa verfasst wurde. Im Anschluss daran präsentierte H. H. Prof. J. M. Dyduch in seiner Laudatio die wichtigsten Begründungen für die Verleihung des Ehrendoktortitels, wobei er unter anderem darauf verwies: „Zusammenfassend kann man feststellen, dass Erzbischof Celestino Migliore eine bedeutende und herausragende Persönlichkeit in der kirchlichen Diplomatie darstellt, die 
weltweit anerkannt ist. Er ist nicht nur ein prominenter Diplomat sondern ebenso ein guter Hirte, der das Volk Gottes zu Jesus, dem Erlöser hinführt im Einklang mit dem traditionellen kanonischen Grundsatz salus animarum suprema lex esto. Die Entscheidung des Senats der Päpstlichen Universität Johannes Paul II. in Krakau, dem Apostolischen Nuntius das Doktorat honoris causa zu verleihen, ist in der Gesamtheit als fundiert und in jeder Hinsicht als berechtigt anzuerkennen. Exzellenz, wir danken für Ihren Dienst an der Kirche, für die Treue gegenüber den höchsten Würdenträgern der Kirche, insbesondere für die Treue zum heiligen Johannes Paul II., dem Namenspatron unserer Universität. Wir danken für die Freundschaft und das Wohlwollen, das Sie den Menschen, Polen, Krakau und der Päpstlichen Universität Johannes Paul II. entgegenbringen. Wir wünschen weiterhin gute Gesundheit sowie viel Erfolg und reiche Früchte bei der schwierigen Arbeit zum Wohl der Kirche und der Menschheit. Dem Dank und den guten Wünschen wollen wir mit dem Geschenk des Ehrendoktorats unserer Universität besonderen Ausdruck verleihen. Ad multos annos!”. Nachdem H. H. Prof. Dr. hab. Józef Stala, Prorektor, das in lateinischer Sprache verfasste Diplom des Doktorats honoris causa verlesen hatte, endete H. H. Prof. Dr. hab. Wojciech Zyzak, Rektor der Päpstlichen Universität Johannes Paul II. in Krakau mit folgenden Worten: „Reverendissimae Excellentiae nomen et dignitatem doctoris honoris causa, nomine Senatus Pontificiae Universitatis Cracoviensis Ioannis Pauli II conferimus". Damit überreichte er Erzbischof C. Migliore feierlich die Auszeichnung als Doktor honoris causa der Päpstlichen Universität Johannes Paul II. in Krakau.

Als nächster Programmpunkt der Zeremonie schloss sich die Rede des geehrten Erzbischofs C. Migliore an, die sich mit dem gesellschaftlichen Format als Lebensraum in der Beziehung mit den Mitmenschen und der Transzendenz befasste. Darin betonte er unter anderem: „Wenn Papst Franziskus von der zentralen Stellung der Armen spricht, in denen wir den 'Leib Christi` wieder finden, dann betreibt er keinen leichtfertigen Pauperismus sondern interpretiert die menschliche Realität im Licht Christi, der sie zu seiner eigenen machte, indem er die Menschen als Kinder Gottes und damit als seine Brüder und Schwestern betrachtete. Diese Vision vom Menschen, gesehen im Licht Christi, hat ihren großen kritischen Wert, aber gleichzeitig auch ihren korrektiven und konstruktiven Vorzug gezeigt, wo es um die anthropologischen Verwirrungen der heutigen Kultur ebenso wie um jegliche Anzeichen von Ungerechtigkeit, Konflikten, Gewalt und Diskriminierung geht. Wie mir scheint, sollen aus dieser Perspektive die akademischen, bildenden und erziehenden Zentren, 


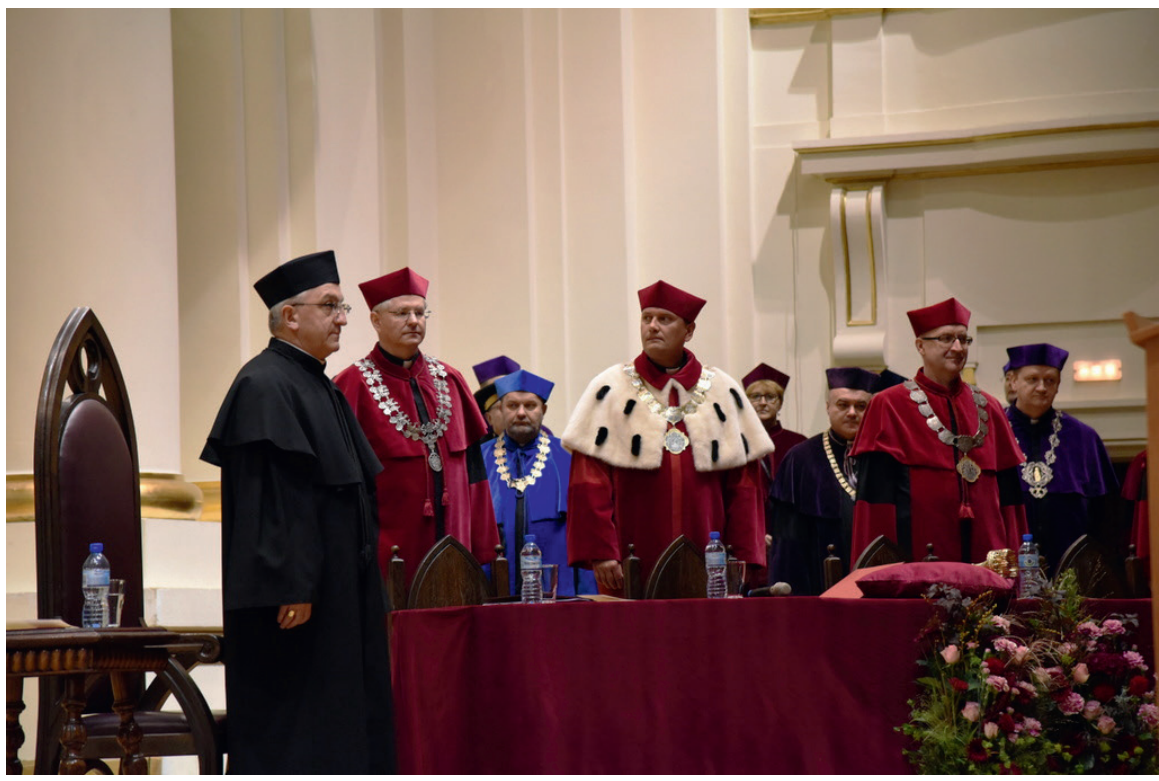

insbesondere die mit christlicher, katholischer Prägung, neuartige, kreative und programmatische Visionen von der Welt ausarbeiten und damit ihren eigenen Beitrag zur Erschaffung einer Welt leisten, in der ein besseres Leben möglich ist. Das wünsche ich auch der Päpstlichen Universität Johannes Paul II. in Krakau, die mich heute mit der Verleihung ihrer höchsten Auszeichnung geehrt hat".

Die festliche musikalische Umrahmung der Feier übernahm der Chor „Psalmodia” der Päpstlichen Universität Johannes Paul II. in Krakau. Zum Abschluss wandte sich der Rektor, H. H. Prof. W. Zyzak, wiederum an den neuen Ehrendoktor der Universität: „Eure Exzellenz, ehrwürdiger Erzbischof! Ich möchte Eurer Exzellenz noch einmal im Namen der gesamten akademischen Gemeinschaft unserer Hochschule von Herzen gratulieren. Unser und mein besonderer Dank gebührt Ihnen für die bisher geleistete wissenschaftliche Forschungsarbeit auf dem Gebiet des Kanonischen Rechts sowie für Ihren gestalterischen Beitrag zur Fortentwicklung der Zusammenarbeit zwischen dem Apostolischen Stuhl und Polen. Wir wünschen viel Gesundheit und Gottes reichen Segen für die weiteren Arbeitsjahre! Ad multos annos, verehrter Preisträger!". 